\title{
Correction of Linoleic Acid Deficiency in Cystic Fibrosis
}

\author{
ELAINE H. MISCHLER, SARA W. PARRELL, PHILIP M. FARRELL, WILLIAM J. RAYNOR, AND \\ RICHARD J. LEMEN \\ Department of Pediatrics, Nursing, and Statistics, University of Wisconsin-Madison, Madison, Wisconsin 53792 \\ and the Department of Pediatrics and Physiology, University of Arizona-Tucson, Tucson, Arizona 85724
}

\begin{abstract}
To identify evidence of essential fatty acid deficiency, we screened 64 patients with cystic fibrosis by analyzing total lipid extracts from plasma. Forty-three had an abnormal linoleate (18:2) level (less than 26\%). Thirteen deficient patients (aged 10-24 yr) ingested for 1 yr $7 \%$ of their total calories as linoleate derived from a daily supplement of Microlipid. Five deficient patients (aged 10-37 yr) served as controls. Plasma and erythrocyte fatty acid composition were monitored by gas chromatography of total lipid extracts seven times during the twelve month period. Prostaglandins $E_{2}$ and $F_{2 \alpha}$ and their 15 keto 13, 14 dihydrometabolite, 6-keto $F_{1 \alpha}$, and thromboxane $B_{2}$ were measured by radioimmunoassay. Sweat tests, oxygen saturation, growth indices, clinical severity scores, compliance, and possible side effects from taking Microlipid were followed. Results showed that oral supplementation with Microlipid can significantly increase plasma and erythrocytes \%18:2. One compliant patient died during the study and had normal tissue 18:2 levels. Nine of 13 patients gained more weight while taking Microlipid than in the previous year. No significant changes in sweat electrolytes, clinical scores, or oxygen saturation were found during the study year. Prostaglandin metabolites prostaglandin $\mathrm{E}_{2}$ showed an upward trend in supplemented patients, compared to controls. Prostaglandin $F_{2 \alpha}$ remained unchanged over 1 yr but showed a trend significantly downward over the final 6 months in supplemented patients. We conclude that linoleate deficiency can be corrected with daily Microlipid supplements and that correction may alter prostaglandin metabolism (Pediatr Res 20: 36-41, 1986)
\end{abstract}

\section{Abbreviations}

CF, cystic fibrosis

18:2, linoleate

PGM, 13,14-dihydro-15-PGF ${ }_{2 \alpha}$

PG, prostaglandin

EFA, essential fatty acid

$\mathrm{RBC}$, red blood cells

Several workers (1-3) have demonstrated markedly decreased concentration of essential fatty acid (EFA) in plasma from CF patients. The major changes include a decreased level of the predominant EFA, linoleate (18:2), and increased palmitoleate

Received October 15, 1984; accepted August 21, 1985

Correspondence and requests for reprints to Dr. Elaine H. Mischler, H4/434 Clinical Sciences Center, University of Wisconsin-Madison, 600 Highland Avenue, Madison, WI 53792.

This study was made possible by a research grant from Organon Pharmaceuticals and a research grant and CTR Center grant from the National Cystic Fibrosis Foundation.
(16:1) and oleate (18:1). A variety of proposals has been offered to account for these abnormalities including pancreatic insufficiency leading to malabsorption of fatty acids (4), reduced dietary intake of fats containing 18:2, and liver disease in CF which causes reduced production of bile acids and thus increases fat malabsorption (5). Of greater importance than abnormal fatty acid levels is the potential for these fatty acid alterations to cause growth retardation, membrane dysfunction, and specifically derangement of prostaglandin metabolism which could affect lung function in CF. Previous studies attempting to assess 18:2 supplementation $(6,7)$ have had mixed success, but have demonstrated that low 18:2 levels occur commonly in CF. Because other studies have not looked comprehensively at effectiveness of supplementation and biochemical and clinical results of supplementation, we believed it was important again to assess feasibility and success of 18:2 supplementation in patients with $C F$ and to comprehensively examine the influence of supplementation on clinical status, red cell membrane, fatty acid composition, and selected biochemical parameters including PG metabolites. Many pieces of the puzzle of the biochemistry of CF have been studied but only by looking at the whole picture can importance of individual puzzle pieces be understood.

\section{MATERIALS AND METHODS}

Patient selection. Sixty-four randomly selected patients aged 7 yr or older cared for at the University of Wisconsin Cystic Fibrosis Care, Teaching and Research Center had measurements of fatty acid composition of plasma total lipid extracts. These subjects were at least $1 \mathrm{~h}$ postprandial at the time of blood drawing. Fifteen, or 35\%, of the EFA-deficient patients aged 1024 yr (plasma 18:2 $<26 \%$ of total fatty acid) agreed to take Microlipid (Microlipid graciously supplied by Organon Pharmaceuticals) (safflower oil emulsion containing $72 \%$ linoleate) in a dose such that $18: 2$ supplied $7 \%$ of their total daily caloric intake for $1 \mathrm{yr}$. The supplement was given along with pancreatic enzymes. Any patient not tolerating Microlipid or showing poor compliance would have been removed from the study at $6 \mathrm{wk}$ but no patient had difficulty. Supplemented patients all had pancreatic insufficiency evidenced by clinical symptoms, a plasma carotene level below $50 \mu \mathrm{g} / \mathrm{dl}$, and a previously demonstrated need for vitamin $\mathrm{E}$ supplementation as indicated by a plasma tocopherol level less than $500 \mu \mathrm{g} / \mathrm{dl}$. Thirteen patients completed the study with two patients dying at 7 and 9 months, respectively. Five other EFA deficient CF patients (ages 10-37 yr) were studied identically but did not receive supplemental linoleate and served as concurrent controls. The protocol was approved by the University of Wisconsin Committee for the Protection of Human Subjects and informed consent obtained from each participant.

Procedure. All patients admitted to the study were taught to record a 4-day diet history. Dietary records were obtained at the 
start of the study and at three month intervals. These results were analyzed by computer (8) for fatty acid, protein, fat, and carbohydrate content as well as total caloric intake. All patients had a quantitative sweat test by the method of Gibson and Cooke (9) of pilocarpine iontophoresis, plasma fatty acid profile, red blood cell fatty acid analysis, plasma carotene, tocopherol, tests intended to detect any possible side effects of Microlipid (platelet count, serum cholesterol, triglycerides, and $\gamma$ glutamyl transferase), and measurement of plasma prostaglandin metabolites (6keto $\mathrm{F}_{1 \alpha}$, thromboxane $\left.\mathrm{B}_{2}, \mathrm{PGE}_{2}, \mathrm{PGF}_{2 \alpha}, \mathrm{PGM}\right)$ at the initiation of the study. Pulmonary function tests including oxygen saturation by ear oximetry, spirometry including forced vital capacity, forced expiratory volume in $1 \mathrm{~s}$, maximum midexpiratory flow, peak flow, and maximum voluntary ventilation done on a Warren E. Collins modular lung analyzer, a chest radiograph, measurement of height, weight, and skinfold thickness, clinical assessment, and NIH clinical severity scoring (10) were also part of the initial assessment.

After dietary analysis, Microlipid was given at a dose of approximately $1 \mathrm{ml} / \mathrm{kg} /$ day which calculated to provide linoleate as $7 \%$ of the total daily caloric intake. At 2,6, and $12 \mathrm{wk}$ after starting Microlipid, and every 3 months thereafter, the initial assessment was repeated except for the sweat test, spirometry, and chest radiographs which were repeated at 6 and 12 months. Initially, patients were asked to come to the clinic in a fasting state but compliance was poor secondary to long distances traveled by several subjects who became ill if traveling on an empty stomach. Therefore, subjects were told to eat a nonfat containing breakfast and were at least $1 \mathrm{~h}$ postprandial at the time of blood sampling. Compliance was assessed at each visit and by a questionnaire administered by EHM at 6 and 12 months. Subjects were asked how Microlipid was taken, how they felt about taking Microlipid, how often they missed a dose, and what side effects (feeling of fullness, nausea, vomiting, loss of appetite, bad aftertaste, diarrhea, stomach cramps), if any, were noted.

Techniques. Plasma and red cell fatty acid analyses were performed using procedures established in this laboratory (11). In general, plasma samples were extracted for total lipid by the Bligh and Dyer (12) technique, methyl esters were prepared by transesterification with methanol/ $\mathrm{BF}_{3}$, and gas chromatography was carried out using a Hewlett-Packard 5830A instrument. Samples were stored at $-20^{\circ} \mathrm{C}$ until analyzed, but erythrocytes were always extracted within 2 days of collection. Autopsies were performed within $24 \mathrm{~h}$ on the two patients who died during the study and tissues obtained (heart, lung, liver, psoas muscle, and perirenal fat) were extracted for total lipids by the method of Radin (13). The final washed chloroform layer was dried under nitrogen, transesterified, and then gas chromatography performed to evaluate the fatty acid composition.

The normal values for plasma and red cell fatty acids were determined by studying 24 healthy children and young adults (most of whom were employees of the University of Wisconsin or their children) aged 3-35 yr. Normal values for linoleate levels in tissues of children were obtained at autopsies performed on a 0.6 yr old who died of Reye's syndrome (liver was not abnormal in fatty acid composition), a 1.4 yr old who died of laryngomalacia with cor pulmonale, heart failure, and respiratory arrest, and frozen samples of tissues from the National Diabetes Foundation of children aged $0.4-11$ yr of age who died unexpectedly but who had good nutrition. Four to six sets of normal pediatric tissue specimens were obtained from the above for fatty acid analysis. The tissue values for a control group of $\mathrm{CF}$ patients were obtained from six adolescent patients with malabsorption who died of chronic lung disease and cor pulmonale.

Analysis of tocopherol (vitamin E) in plasma was carried out by colorimetric methods applied to plasma lipid extracts, as described previously (14); this technique permits simultaneous determination of carotene.

Blood samples $(20 \mathrm{ml})$ for plasma PG measurements were drawn from the antecubital vein into plastic syringes. The sam- ples were withdrawn slowly using gentle mixing to minimize hemolysis. The blood was immediately transferred to chilled polypropylene tubes containing $1.6 \%$ indomethacin $(0.01 \mathrm{ml} / \mathrm{ml}$ blood) and $2 \%$ EDTA $(0.09 \mathrm{ml} / \mathrm{ml}$ blood $)$ and centrifuged at $2000 \times g, 4^{\circ} \mathrm{C}$, for $30 \mathrm{~min}$. The plasma was pipetted into polypropylene tubes and frozen at $-70^{\circ} \mathrm{C}$ until analysis. These frozen samples were coded and mailed by overnight mail packed in dry ice to Dr. Richard Lemen for analysis.

Plasma PGs were extracted with ethyl acetate-petroleum ether followed by column separation (15). The percent recovery (60$90 \%$ for all PGs) was measured for each study and was included in a correction factor when calculating plasma concentrations. Prostaglandins were measured by radioimmunoassay using single antibody techniques. The stable metabolites of $\mathrm{PGI}_{2}$ and $\mathrm{TxA}$, i.e. 6-keto-PGF $\mathrm{F}_{1 \alpha}$ and $\mathrm{TxB}_{2}$ were measured respectively, as well as $\mathrm{PGE}_{2}, \mathrm{PGF}_{2 \alpha}$, and PGM. Standards were run in duplicate with each assay and plasma samples were run in triplicate. Data were reported as mean values. Tritiated PGs and PG standards were purchased from New England Nuclear Co. and Upjohn Co., respectively. Antibodies to 6-keto-PGF $\mathrm{PG}_{1 \alpha}, \mathrm{TxB}_{2}, \mathrm{PGE}_{2}$, and $\mathrm{PGF}_{2 \alpha}$ were purchased from Seragen, Inc. Antibody to PGM was provided by Dr. Ray Haning, University of Wisconsin School of Medicine.

Plasma exhibits parallelism to pure PG standard curves in concentrations of $30-2000 \mathrm{pg} / \mathrm{ml}$. This indicates the absence of inhibitors to PG binding. The within-sample coefficient of variation was $1-10 \%$ for standards and $10-25 \%$ for plasma. The sensitivities of the assays are: 6-keto-PGF ${ }_{1 \alpha}-10 \mathrm{pg} / \mathrm{ml} ; \mathrm{TxB}_{2}-$ $3 \mathrm{pg} / \mathrm{ml} ; \mathrm{PGE}_{2}-25 \mathrm{pg} / \mathrm{ml} ; \mathrm{PGF}_{2 \alpha}-30 \mathrm{pg} / \mathrm{ml} ; \mathrm{PGM}-95 \mathrm{pg} /$ $\mathrm{ml}$. Antibody cross-reactivity was measured at less than $2 \%$ for all PGs except for PGM which reacts equally with the analogous $\mathrm{PGE}_{2}$ metabolite within our range (16). Standard curves were linearized using logit transformation and plasma levels were calculated with a programmable calculator.

Data analysis was accomplished using the paired Student's $t$ test and nonparametric testing. Comparison of $\mathrm{NIH}$ scores, $\mathrm{O}_{2}$ saturation by ear oximetry, sweat test results, and comparison of plasma and erythrocyte 18:2 levels before and after supplementation was done by paired Student's $t$ test. The PG concentrations were tested for time trends using a pooled $\tau \gamma$, Kendall's nonparametric correlation coefficient (17). This statistic compares the number of increasing pairs of data points (i.e. $\mathrm{X},>\mathrm{X}_{2}$ and $\left.Y,>Y_{2}\right)$ with the number of decreasing pairs $\left(X,>X_{2}\right.$ and $Y$, $>\mathrm{Y}_{2}$ ). The number of increasing and decreasing pairs was determined for each patient. The correlation coefficient is the difference between the within group total number of increasing pairs minus the within group total decreasing pairs divided by their sum. The exact mean and variance for the number of increasing pairs was calculated for each person under the assumption of no time trend. A $Z$ statistic was calculated for each person, and these were combined to form the $\mathrm{Z}$ statistic for the entire group.

\section{RESULTS}

Patients were coded with a letter of the alphabet. The five controls are A through $\mathrm{E}$ and the 13 supplemented patients are $\mathrm{F}$ through $\mathrm{R}$. Screening plasma carotene values were low $(<50$ $\mu \mathrm{g} / \mathrm{dl}$ ) in all subjects at the initiation of the study indicating the presence of malabsorption. Table 1 illustrates the clinical scores, growth, and dietary assessment data in both patient groups. As noted, NIH scores did not change significantly for either group over the period of supplementation. Supplemented patients did not have a significant change in calories or non-Microlipid linoleate intake over the 12 -month period of time. The diets of the supplemented and control patients provided averages of 8.6 $\mathrm{g}$ and $2.8 \%$ cal as linoleate, respectively, which is equal to the recommended dietary allowance of $3 \%$ of total daily calories provided by linoleate (18). Nine of 13 supplemented patients gained more weight during the 2 nd yr while taking Microlipid, whereas two control patients gained more weight during the 
Table 1. Clinical scores, growth, and dietary assessment data

\begin{tabular}{|c|c|c|c|c|c|c|c|c|c|}
\hline \multirow{2}{*}{$\begin{array}{c}\text { Supplemented } \\
\text { patients }\end{array}$} & \multicolumn{2}{|c|}{ NIH score* } & \multicolumn{2}{|c|}{$\begin{array}{l}\text { Average daily*, } \dagger \\
\text { calories }\end{array}$} & \multicolumn{2}{|c|}{$\begin{array}{c}\text { Average* } \dagger \\
\text { nonsupplement } \\
\text { 18:2 intake (g) }\end{array}$} & \multicolumn{3}{|c|}{ Wt in $\mathrm{kg} !$} \\
\hline & $0 \mathrm{Mo}$ & $12 \mathrm{Mo}$ & $0 \mathrm{Mo}$ & $12 \mathrm{Mo}$ & $0 \mathrm{Mo}$ & $12 \mathrm{Mo}$ & $-12 \mathrm{Mo}$ & $0 \mathrm{Mo}$ & $+12 \mathrm{Mo}$ \\
\hline $\mathrm{F}$ & 74 & 76 & 1682 & $-\S$ & 5.3 & 0.0 & 35.5 & 39.3 & 38.1 \\
\hline G & 78 & 85 & 2089 & 3275 & 11.7 & 18.1 & 40.5 & 45.0 & 51.6 \\
\hline $\mathrm{H}$ & 88 & 86 & 2370 & 2226 & 8.8 & 10.8 & 37.3 & 44.7 & 49.6 \\
\hline I & 74 & 64 & 1849 & 1807 & 6.2 & 7.0 & 29.1 & 30.5 & 34.1 \\
\hline K & 84 & 94 & 2105 & 3277 & 2.7 & 9.3 & 36.2 & 37.6 & 45.0 \\
\hline $\mathrm{L} \|$ & 75 & 76 & 2208 & 3378 & 32.0 & 15.7 & 70.2 & 70.5 & 70.0 \\
\hline M & 92 & 90 & 3184 & 3407 & 15.4 & 14.9 & 51.4 & 52.3 & 55.0 \\
\hline $\mathrm{N}$ & 74 & 81 & 3643 & - & 10.0 & - & 27.4 & 31.4 & 38.6 \\
\hline $\mathrm{O}$ & 94 & 97 & 5352 & 3478 & 9.6 & 12.6 & 39.8 & 44.2 & 52.6 \\
\hline $\mathbf{P}$ & 82 & 88 & 2590 & 2708 & 3.0 & 3.6 & 26.8 & 29.2 & 32.0 \\
\hline Q & 82 & 87 & 3443 & 3172 & 8.5 & 9.2 & 41.8 & 48.3 & 55.0 \\
\hline \multicolumn{10}{|l|}{ Control patients } \\
\hline $\mathrm{A} \|$ & 62 & 64 & 3324 & 3009 & 2.7 & 12.9 & 40.2 & 40.8 & 39.5 \\
\hline B & 93 & 93 & - & 2435 & - & 5.0 & 30.0 & 32.2 & 35.9 \\
\hline $\mathrm{C} \|$ & 72 & 41 & - & 2833 & - & 12.7 & 49.1 & 49.5 & 45.5 \\
\hline $\mathrm{D}$ & 43 & 48 & 1734 & - & 4.9 & - & 26.8 & 25.4 & 26.8 \\
\hline E & 83 & 87 & 2795 & - & 2.2 & - & 40.0 & 48.2 & 51.4 \\
\hline Mean $\pm S D$ & $71 \pm 19$ & $67 \pm 23$ & $2618 \pm 810$ & $2759 \pm 294$ & $3.3 \pm 1.4$ & $10.2 \pm 4.5$ & & & \\
\hline
\end{tabular}

* No significant change when comparing time 0 to $12 \mathrm{mo}$.

$\dagger$ Control data not compared by Student's $t$ test because numbers so few.

$\$-12$ months $=1$ yr before study, $0=$ start study, $+12=$ finish study.

$\S$ Data not available.

$\| \geq 20$ yr of age.

Table 2. Plasma and RBC \% 18:2 (mean $\pm S D$ ) of total fatty acids

\begin{tabular}{|c|c|c|c|c|}
\hline \multirow{2}{*}{$\begin{array}{c}\text { Time in } \\
\text { Mo* }^{*}\end{array}$} & \multicolumn{2}{|c|}{ Plasma \% 18:2† } & \multicolumn{2}{|c|}{$\mathrm{RBC} \% \quad 18: 2$} \\
\hline & Supplemented & Control & Supplemented & Control \\
\hline 0 & $22.80 \pm 3.82$ & $19.15 \pm 4.21$ & $10.27 \pm 1.20$ & $9.09 \pm 1.62$ \\
\hline 6 & $27.46 \pm 5.07$ & $20.77 \pm 4.70$ & $12.23 \pm 1.56$ & $9.14 \pm 1.23$ \\
\hline 9 & $28.19 \pm 5.80$ & $22.19 \pm 4.06$ & $11.79 \pm 1.66$ & $8.40 \pm 2.22$ \\
\hline 12 & $28.73 \pm 4.16 \ddagger$ & $20.83 \pm 2.21(\mathrm{NS})$ & $11.94 \pm 1.43 \S$ & $9.51 \pm 0.79(\mathrm{NS})$ \\
\hline
\end{tabular}

* Study period.

$\uparrow$ Normal $=34.65 \pm 3.91$.

$\mp$ Significant at $p<0.000 \mathrm{I}$ when compared to time 0 .

$\S$ Significant at $p<0.0005$ when compared to time 0 .

study year. Thus, although caloric intake did not change significantly, growth of nine supplemented adolescents (age less than 20 yr) was enhanced with Microlipid. No significant changes in oxygen saturation or sweat chloride values were noted in either group over the year study period and therefore results were not included in Table 1. Both groups had a mean oxygen saturation of $94 \%$. Sweat chloride results of the control group ranged from 97 to $128 \mathrm{mEq} / \mathrm{liter}$ and varied 2 to $8 \mathrm{mEq} /$ liter over the study year. Sweat chloride values ranged from 81 to $127 \mathrm{mEq} /$ liter in the Microlipid group at the beginning of the study and 87 to 127 $\mathrm{mEq} /$ liter at the end of the study.

Patient compliance, evaluated by interviews and questionnaires administered by EHM, was excellent. Eighty-five percent took all doses or missed only one to two doses per week of Microlipid. Opinions concerning subjective side effects from taking Microlipid as well as reasons for taking it were solicited. Minor symptomatic side effects from taking the supplement were a feeling of fullness reported by three patients, nausea in three, loss of appetite in two, bad aftertaste reported by three, stomach cramps in three, and diarrhea occurred in two subjects. Three of 13 respondents reported that an unpleasant aftertaste was a major side effect. Reasons volunteered for taking Microlipid included that it would improve their health according to 12 respondents. Nine subjects reported that they were taking Microlipid to help $\mathrm{CF}$ research. No subject thought Microlipid tasted good and three reported they would quit as soon as the 12-month study period was completed.

Table 2 describes the plasma and RBC \% 18:2 of total fatty acids at the beginning of the study (time 0 ) and every 3 months thereafter. Compared to the normal mean values in our laboratory $(34.65 \pm 3.91)$, the mean $18: 2$ levels of the supplemented patients at 3 months had risen above the normal mean -2 SD and were significantly elevated $(p<0.0001)$ at the end of the study period when compared to time 0 . The same trend was observed in RBC \% 18:2 ( $\mathrm{p}<0.0005)$. The control group remained deficient in plasma and $\mathrm{RBC} 18: 2$ throughout the study. Arachidonate levels $(20: 4 \omega 6)$ did not change with supplementation. Although 11 supplemented subjects had detectable 


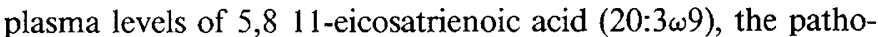
logic triene found in EFA deficient individuals (19) at the start of the study, only four had detectable levels after one year of supplementation. In the control group, five of five individuals

\section{Tissue Linoleate in Cystic Fibrosis}

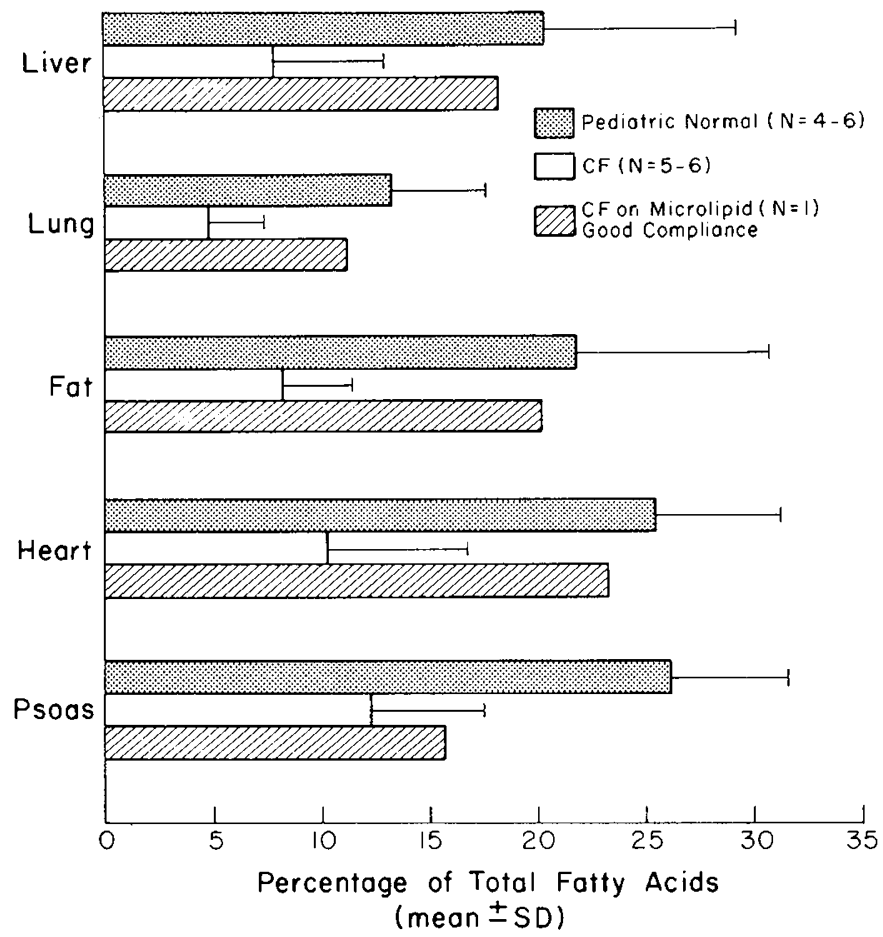

Fig. 1. Tissue linoleate in CF. \%18:2 in autopsy tissues of cystic fibrosis patients is compared to a supplemented $\mathrm{CF}$ patient and normal children. had 20:3 $\omega 9$ detected throughout the study.

The linoleate concentrations in tissues from a compliant study patient who died at 6 months compared to linoleate tissue data from nonsupplemented CF patients and normal children are shown in Figure 1. The supplemented patient dying at 9 months described significant noncompliance in taking the supplement and tissue results could not be interpreted, whereas the other supplemented patient rarely missed a dose of Microlipid. This patient had tissues which contained percent linoleate levels within $1 \mathrm{SD}$ of normal except for levels of 18:2 in psoas muscle which was within 2 SD of normal.

Representative prostaglandin data for supplemented and control patients are presented in Table 3 . A weighted average is obtained as the baseline level by averaging the result of the 0-, 2-, and 6-wk sample for each parameter. Because SDs were large for the PG metabolites measured at each of seven different intervals, PG levels were evaluated for time trends during the year using the pooled Kendall's $\tau$ (17). A positive $\mathrm{Z}$ statistic indicated an upward trend and a negative $Z$ statistic a downward trend. Table 4 describes the results of this analysis for metabolite 6-keto- $\mathrm{F}_{1 \alpha}$, thromboxane $\mathrm{B}_{2}, \mathrm{PGM}, \mathrm{PGF}_{2 \alpha}$, and $\mathrm{PGE}_{2}$ for the entire year and the period 6 to 12 months. Over the 1 -yr period, metabolite 6-keto- $F_{1 \alpha}$, thromboxane $B_{2}$, and PGM all were significantly increased in both the Microlipid and the control groups. $\mathrm{PGE}_{2}$ increased in the supplemented group with $\mathrm{PGF}_{2 \alpha}$ not changing significantly; however, the control group had a decreasing trend in $\mathrm{PGF}_{2 \alpha}$. Focusing on an analysis of the last 6 months of the study using a one-sided $p$ (compliance was unchanged), we found that the controls show only a significant increase in 6-keto- $\mathrm{F}_{1 \alpha}$ and decreased $\mathrm{PGF}_{2 \alpha}$, whereas all of the metabolites were significantly increased in the supplemented group except $\mathrm{PGF}_{2 \alpha}$, which showed a decrease $(p<0.02)$.

\section{DISCUSSION}

In this study, we found $67 \%$ of screened $\mathrm{CF}$ patients to be deficient in 18:2, even though their diets provided an average of

Table 3. $P G$ data (mean $\pm S D$ in $p g / m l)$ in supplemented ${ }^{*} C F$ patients $(n=13)$ and control patients $(n=5)$

\begin{tabular}{|c|c|c|c|c|c|c|}
\hline & \multicolumn{3}{|c|}{ Control } & \multicolumn{3}{|c|}{ Supplemented } \\
\hline & Baseline $†$ & $6 \mathrm{Mo}$ & $12 \mathrm{Mo}$ & Baseline $†$ & $6 \mathrm{Mo}$ & $12 \mathrm{Mo}$ \\
\hline $\mathrm{PGF}_{2 \alpha}$ & $243 \pm 243$ & $271 \pm 132$ & $33 \pm 63$ & $107 \pm 90$ & $320 \pm 130$ & $133 \pm 151$ \\
\hline
\end{tabular}

* Supplemented over 12-mo period.

$\dagger$ Weighted average of time $0-, 2$-wk, 6-wk samples.

Table 4. Analysis of PG time trends*

\begin{tabular}{|c|c|c|c|c|c|c|c|}
\hline & \multicolumn{3}{|c|}{ All quarters } & \multicolumn{3}{|c|}{ 6-9-12 Mo } & \\
\hline & & & One-sided & & & One-sided & \\
\hline & $\hat{\tau}_{\gamma} \dagger$ & $\mathrm{Z \ddagger}$ & $p$ & $\hat{\tau}_{\gamma}$ & Z & $p$ & \\
\hline $6-$ Keto- $F_{1 \alpha}$ & 0.53 & 2.99 & $<0.002$ & 1.00 & 3.25 & $<0.001$ & \\
\hline Thromboxane $\mathrm{B}_{2}$ & 0.42 & 1.75 & $<0.04$ & 0.36 & 1.38 & $<0.08$ & \\
\hline PGM & 0.69 & 1.65 & $<0.05$ & 0.87 & 1.23 & NS & \\
\hline \multicolumn{7}{|l|}{ Microlipid group } & \\
\hline $6-$ Keto-F $F_{1 \alpha}$ & 0.33 & 2.65 & $<0.004$ & 0.83 & 3.61 & $<0.001$ & \\
\hline Thromboxane $B_{2}$ & 0.30 & 2.10 & $<0.02$ & 0.35 & 1.82 & $<0.03$ & \\
\hline PGM & 0.51 & 3.23 & $<0.001$ & 0.57 & 2.55 & $<0.005$ & \\
\hline $\mathrm{PGF}_{2 \alpha}$ & 0.08 & 0.85 & NS & -0.34 & -2.01 & $<0.02$ & \\
\hline $\mathrm{PGE}_{2}$ & 0.38 & 2.26 & $<0.01$ & 0.40 & 2.31 & $<0.01$ & \\
\hline
\end{tabular}

* No significant trends noted in 0 - to 6-month time interval using one-sided $p$.

$\dagger$ Pooled Kendall's $\tau(17)$ is the weighted sum of $(C-D)$ over the weighted sum of $(C+D)$ where $C$ is the within person concordant pairs, $D$, the discordant pairs.

$\$$ Calculated as the sum of the within person $\mathrm{Z}$ statistics using the permutation mean and variance of $\mathrm{C}$. 
$40 \%$ total calories as fat. Oral supplementation with Microlipid did increase significantly both plasma \%18:2 and RBC \%18:2. It should be recognized that the supplement was taken with pancreatic enzyme replacement in the form of enteric coated microspheres which we have unequivocally shown to be more effective in promoting absorption than the enzyme powder preparations used previously (20). The use of this type of enzyme plus compliance in taking Microlipid may explain why normalization of plasma and 18:2 levels was readily achieved in this study at a dose of approximately $0.45 \mathrm{~g} / \mathrm{kg} /$ day of linoleate. Tissue levels of the compliant patient studied at autopsy showed twice the mean 18:2 level of nonsupplemented CF patients and within 1 $\mathrm{SD}$ of the pediatric normals except in psoas tissue. This confirmed the positive effect of oral linoleate supplementation and indicates that the large body pool of $18: 2$ can be normalized in CF patients with malabsorption.

The effects of severe linoleic acid deficiency in animals have long been appreciated as the classical effects of EFA deficiency (21). Major abnormalities include growth failure, a scaly dermatitis, impaired development of reproductive systems, and an increased basal metabolic rate. In addition, it has been observed that EFA-deficient mice show decreased resistance to bacterial infection and that chicks may show chronic respiratory disease associated with accumulation of tenacious, purulent exudate in secondary bronchi (22). It has further been demonstrated (23) that EFA-deficient rats show marked changes in the fatty acid substructure of lung surfactant phospholipids, possibly leading to alveolar instability. The underlying cause of the above disorders is thought by some investigators to be a general alteration in membrane phospholipid structure $(21,24)$. Another possibility relates to altered $\mathrm{PG}$ production since linoleate and its elongation/desaturation product arachidonate are converted to a variety of these important compounds (25). Meydani et al. (26) noted an 8-fold increase in $\mathrm{PGF}_{2 \alpha}, 13$-fold increase in $\mathrm{PGE}_{2}$, and an 11 -fold increase in $\mathrm{PGE}_{\mathrm{f}}$, in rat lungs when the animals were fed safflower oil. Since EFA are required for PG synthesis, it is reasoned that reduced availability of precursors might decrease the formation of these biologically active substances with widespread physiologic consequences.

In humans, EFA deficiency has been described by Hansen et al. (27) in infants who have desquamating skin lesions, poor wound healing, thrombocytopenia, increased susceptibility to infection, and poor growth. Chase et al. (5) described a 5-yr-old girl with CF with a scaly rash of the face which disappeared following linoleic acid supplementation. Other possible consequences could be expected in humans such as altered fatty acid metabolism and PG synthesis as well as membrane dysfunction. $\mathrm{PGF}_{2 \alpha}$ and $\mathrm{TxA}_{2}$ are associated with bronchoconstriction and airway obstruction and could possibly be related to the pulmonary pathophysiology in CF. Chase and Dupont (6) found that patients with $\mathrm{CF}$ and low linoleic acid levels had increased $\mathrm{PGF}_{2 \alpha}$. Lemen et al. (28) and Dubois et al. (29) have reported increased plasma and serum $\mathrm{PGF}_{2 \alpha}$ concentration in $\mathrm{CF}$ individuals. On the other hand, Lloyd-Still et al. (30) found the mean PG levels to be in the normal range with a wide distribution of values. Thus, the role of PGs in the pathology of CF has been speculated upon, but the picture remains unclear.

Concern regarding the possible consequences of EFA deficiency in CF prompted Elliot (31) to attempt biochemical correction by intravenous infusion of soya oil emulsion (Intralipid) containing $56 \%$ linoleic acid. Although plasma 18:2 levels were not documented, Elliot (31) reported that the treatment led to improved growth, a decrease in the concentration of sodium in sweat, and a more benign course over 30 months of evaluationcompared to $\mathrm{CF}$ patients not receiving supplements. Beveridge (32) found reduced sweat chloride in two of four patients receiving intravenous supplements of Intralipid over a 2-yr period. Oral supplementation has been examined previously in several studies. Chase and Dupont (6) have shown that linoleic acid monoglyceride given with pancreatic enzymes is absorbed intact and can raise plasma linoleic acid levels in children with $C F$. Rosenlund et al. (33) fed oral corn oil for at least $1 \mathrm{yr}$ and noted a significant decrease in sweat sodium and an increase in levels of arachidonic acid whereas $18: 2$ increased $106 \%$ in the phospholipid fraction. Lloyd-Still et al. (7) fed oral safflower oil $(1 \mathrm{~g} /$ $\mathrm{kg}$ /day) to $11 \mathrm{CF}$ patients for $1 \mathrm{yr}$, but was unable to correct 18:2 deficiency and or to produce a significant change in sweat chloride concentration or sweat rate; there was also no clinical improvement when compared to a control group. Chase et al. (34), in a double-blind study of twice monthly infusions of Intralipid, found clinical improvement of the supplemented children when compared to controls; however, 2 wk after each infusion, plasma and $\mathrm{RBC}$ linoleic acid levels were not increased. Landon et al. (35) concluded that oral hyperalimentation can restore EFA levels in patients with $\mathrm{CF}$ if adequate dietary calories are given to provide energy needs. Their patients received $230 \%$ of calories estimated as requirement for energy expenditure including $40 \%$ as fat. If the patients did not normalize their EFA levels on this diet, they then received an additional $5 \%$ of their caloric intake as linoleic acid monoglyceride. In the patients with normalized EFA levels, it was noted that there was an increase in weight and activity, and also regulation of menses in five adolescent girls.

The relationship of plasma PG concentrations to physiologic factors in CF patients is unclear although possibly important because PGs may have very potent effects on all smooth muscle. Values obtained in this study for PG metabolites had large standard deviations. Certainly there was a trend upward in metabolite $\mathrm{PGE}_{2}$ in supplemented patients. $\mathrm{PGF}_{2 \alpha}$ remained unchanged over $1 \mathrm{yr}$ but showed a trend significantly downward over the final 6 months in supplemented patients. $\mathrm{PGF}_{2 \alpha}$ also showed a significant decrease in control patients with no change in $\mathrm{PGE}_{2}$. Thromboxane $\mathrm{B}_{2}$ showed increases in both groups. It is tempting to suggest that if linoleate levels were maintained in the normal range, over many years decreased $\mathrm{PGF}_{2 \alpha}$ levels and increasing $\mathrm{PGE}_{2}$ levels could have a beneficial effect on airway function in $\mathrm{CF}$ patients since $\mathrm{PGF}_{2 \alpha}$ causes bronchoconstriction and $\mathrm{PGE}_{2}$ bronchial relaxation. Much more data are needed, however, to make the above statement fact. No significant changes were noted in pulmonary function parameters, especially FVC and $\mathrm{FEV}_{1}$ or chest $\mathrm{x}$-ray during the study in supplemented patients to support a beneficial effect of changes in PG levels.

Over the year period of time, there was no change in total caloric intake or linoleate content of food in the supplemented patients. It is therefore tempting to ascribe the weight gain seen in nine of 13 supplemented patients to the addition of Microlipid to their daily caloric intake and the correction of $18: 2$ deficiency per se. These data are difficult to analyze as many of these patients are in the age range where an adolescent growth spurt could be expected. It is possible that there was also a psychologic influence on weight as patients were seen seven times during the 1 -yr period and considerable discussion focused on diet. As stated earlier, however, no significant change occurred in caloric intake over the year period of time. The ingestion of Microlipid caused no significant adverse effects on the supplemented patients as noted by monitoring platelet counts, cholesterol, triglycerides, and $\gamma$ glutamyl transferase. Evaluating oxygenation to assess for pulmonary diffusion abnormalities reported with Intralipid infusion, we found no change in percent oxygen saturation by ear oximetry.

Unlike Rosenlund et al. (33) and Beverage (32), we detected no significant change in sweat sodium and chloride values in the supplemented patients over the 1-yr study period. Our results corroborate those of Lloyd-Still et al. (30).

In conclusion, biochemical correction of plasma, erythrocyte, and tissue linoleate levels by oral supplementation of patients with $\mathrm{CF}$ is possible. With a supplement providing $7 \%$ of calories as $18: 2$, there appears to have been a positive effect on growth and a possible positive effect on PG levels. The statement concerning PGs must be tempered by the fact that control values 
also changed during the study period. This trial was not long enough to judge whether lung function was altered by the changes in fatty acid metabolism and PG metabolites. Whether this effect would continue over a longer period of supplementation needs to be delineated. Future directions which need to be explored in the area of linoleic acid therapy include the long-term effect and significance of supplementation on PGs, growth, and the pulmonary function of children with CF who develop deficiency of 18:2. Such a trial obviously needs to be continued for a prolonged period of time, possibly 5-10 yr. Age- and sex-matched nonsupplemented deficient and nondeficient patients are needed to serve as controls.

Acknowledgments. The authors thank the National Diabetes Research Interchange and Dr. Robert Bergan of Duluth, Minnesota for their assistance in obtaining autopsy specimens. Edward Pohlmann, Jeannette Brown, and Evelyn Dwyer are appreciated for excellent technical assistance. Mrs. Leta Phernetton and Janice Holcomb gave invaluable assistance in typing the manuscript.

\section{REFERENCES}

1. Kuo PT, Huang NN 1965 The effect of medium chain triglyceride upon fat absorption and plasma lipid and depot fat of children with cystic fibrosis of the pancreas. J Clin Invest 44:1924-1933

2. Rivers JP, Hassam AG 1975 Defective essential-fatty-acid metabolism in cystic fibrosis. Lancet 2:642-643

3. Rosenlund ML, Kim HK, Kritchevsky D 1974 Essential fatty acids in cystic fibrosis. Nature 251:719

4. Hubbard VS, Dunn GD, di Sant'Agnese PA 1977 Abnormal fatty-acid composition of plasma-lipids in cystic fibrosis. A primary or a secondary defect? Lancet 2:1302-1304

5. Chase PH, Long MA, Lavin MH 1979 Medical progress. Cystic fibrosis and malnutrition. J Pediatr 95:337-347

6. Chase HP, Dupont J 1978 Abnormal levels of prostaglandins and fatty acids in blood of children with cystic fibrosis. Lancet 2:236-238

7. Lloyd-Still JD, Johnson SB, Holman RT 1981 Essential fatty acid status in cystic fibrosis and the effects of safflower oil supplementation. Am J Clin Nutr 34:1-7

8. Watt BK, Merrill AL 1950 Composition of foods in agriculture. Agricultural Handbook no. 8, Bureau of Human Nutrition and Home Economics Agriculture Research Administration, United States Department of Agriculture, Govt Printing Office, Washington, D.C., pp 10-140

9. Gibson LE, Cooke RE 1959 A test for concentration of electrolytes in sweat in cystic fibrosis of the pancreas utilizing pilocarpine by iontophoresis. Pediatrics 23:545-549

10. Taussig LM, Kattwinkel J, Friedewald WT, di Sant'Agnese PA 1973 A new prognostic score and clinical evaluation system for cystic fibrosis. J Pediatr 82:380-390

11. Gourley GR, Farrell PM, Odell GB 1982 Essential fatty acid deficiency after hepatic portoenterostomy for biliary atresia. Am J Clin Nutr 36:1194-1199

12. Bligh EG, Dyer WJ 1959 A rapid method of total lipid extraction and purification. Can J Biochem Physiol 37:912-917
13. Radin NS 1969 Preparation of lipid extracts. Methods Enzymol 14:245-254

14. Farrell PM, Bieri JG, Fratantoni JF, Wood RE, Fischer WW 1977 The occurrence and effects of human vitamin E deficiency. J Clin Invest 60:233241

15. Green K, Hamberg M, Samuelsson B, Frolich J 1978 Extraction and chromatographic procedures for purification of prostaglandins, thromboxanes, prostacyclines, and their metabolites. In: Frolich JC (ed) Advances in Prostaglandin and Thromboxane Research. Raven Press, New York, pp 15-38

16. Haning RV, Kieliszek FX, Alberino SP, Speroff L 1977 A radioimmunoassay for 13,14-dihydro-15-keto prostaglandin $F_{2 \alpha}$ with chromatography and internal recovery standard. Prostaglandins 13:455-477

17. Hollander M, Wolfe DA 1973 The independence problem. In: Nonparametric Statistical Methods. Wiley and Sons, New York, pp 185-199

18. Recommended Dietary Allowances. 1980 9th ed. Committee on Dietary Allowances, Food and Nutrition Board. National Academy of Sciences, Washington, D.C., p 34

19. Holman RT, Smythe L, Johnson S 1979 Effect of sex and age on fatty acid composition of human serum lipids. Am J Clin Nutr 32:2390-2399

20. Mischler EH, Parrell SW, Farrell PM, Odell GB 1982 Comparison of effectiveness of pancreatic enzyme preparation in cystic fibrosis. Am J Dis Child 136:1060-1063

21. Aaes-Jorgensen E 1961 Essential fatty acids. Physil Rev 41:1-51

22. Hopkins DT, Witter RL, Nesheim MC 1963 A respiratory disease syndrome in chickens fed essential fatty acid deficient diets. Proc Soc Exp Biol Med 114:82-86

23. Kyriakides EC, Beeler DA, Edmonds RH, Balint JA 1976 Alterations in phosphatidylcholine species and their reversal in pulmonary surfactant during essential fatty-acid deficiency. Biochim Biophys Acta 431:399-407

24. Holman RT 1970 Biological activities of and requirements for polyunsaturated acids. Prog Chem Fats Other Lipid 9:612-682

25. Samuelsson B, Granstrom E, Green K, Hamburg M 1971 Metabolism of prostaglandins. In: Ramwell P, Shaw JE (eds) Prostaglandins, vol 180. Ann NY Acad Sciences, New York, pp 138-163

26. Meydani SN, Mathias MM, Schatte CL 1978 Dietary fat type and ambient oxygen tension influence pulmonary prostaglandin synthetic potential. Prostaglandins Med 1:241-249

27. Hansen AE, Wiese HF, Boelsche AN, Haggard ME, Adam D, Davis H 1963 Role of linoleic acid in infant nutrition. Clinical and chemical study of 428 infants fed on milk mixture varying in kind and amount of fat. Pediatrics 31:171-192

28. Lemen RJ, Gates AJ, Mathe AA, Waring WW, Human AL, Kadowitz PD 1978 Relationships among digital clubbing, disease severity, and serum prostaglandins $\mathrm{F}_{2 \alpha}$ and $\mathrm{E}$ concentrations in cystic fibrosis patients. Am Rev Respir Dis 117:639-646

29. Dubois RS, Selley ML, Smith I, Brown JM 1977 Plasma prostaglandin (PG) levels in cystic fibrosis (CF). Gastroenterology 72:1052

30. Lloyd-Still JD, Simon SH, Wessel HU, Gibson LE 1979 Negative effects of oral fatty acid supplementation on sweat chloride in cystic fibrosis. Pediatrics 64:50-52

31. Elliott RB 1976 A therapeutic trial of fatty acid supplementation in cystic fibrosis. Pediatrics 57:474-479

32. Beveridge $\mathbf{J} 1976$ Intralipid and cystic fibrosis. Pediatrics 58:465

33. Rosenlund ML, Selekman JA, Hong KK, Kritchevsky O 1977 Dietary essential fatty acids in cystic fibrosis. Pediatrics 59:428-432

34. Chase HP, Cotton EK, Elliott RB 1979 Intravenous linoleic acid supplementation in children with cystic fibrosis. Pediatrics 64:207-213

35. Landon C, Kerner JA, Castillo R, Adams LA, Whalen R, Lewiston NJ 1981 Oral correction of essential fatty acid deficiency and cystic fibrosis. JPEN 5:501-504 